\title{
Electron Spin Resonance Dating of Fossil Tooth Enamel
}

Mathieu Duval*

ESR dating laboratory, Geochronology program, Centro Nacional de Investigación sobre la Evolución Humana (CENIEH), Burgos, España

\section{Synonyms}

Electron paramagnetic resonance (EPR) dating of fossil tooth enamel

\section{Definitions}

Electron spin resonance (ESR) dating: a chronometric dating method based on the evaluation of the exposure of some materials to natural radioactivity, which is quantified in terms of absorbed radiation dose and corresponds to the energy deposited in the matter by ionizing radiations.

$D_{E}$ : equivalent dose. The total absorbed radiation dose as measured in the laboratory.

ka: 1,000 years.

Ma: $1,000,000$ years.

\section{Introduction}

The first ESR dating applications to fossil bones were published in the early 1980s (e.g., Ikeya and Miki 1980). Given the potential of this kind of material, studies were quickly reoriented toward fossil tooth enamel, which has more suitable characteristics for dating (Grün and Schwarcz 1987). Then, the method progressively gained in accuracy over the following decades, especially via a better understanding of the ESR signal of fossil enamel and its behavior with the absorbed dose. A major advance in ESR dating of enamel resulted from the introduction of a method combining ESR and U-series data in order to model the uranium (U) uptake into dental tissues, thus constraining the uncertainty of the resulting dose rate (Grün et al. 1988). This definitely helped to convert the method into a valuable tool to date fossil remains beyond the ${ }^{14} \mathrm{C}$ time range.

\section{Tooth Enamel: A Natural Biodosimeter,}

From a mineralogical point of view, enamel is mainly made of carbonated hydroxyapatite $\left(\mathrm{Ca}_{10}\left(\mathrm{PO}_{4}\right)_{6}(\mathrm{OH})_{2}\right)(90 \%$, vs. $\sim 70 \%$ for dentine and bone), water $(\sim 3 \%)$, and organic matter $(<1 \%)$ (Elliott 2002). Enamel is denser and more compact than dentine or bone, with larger hydroxyapatite crystals, making it less sensitive to diagenetic changes in terms of microstructure and chemical composition or dissolution/recrystallization processes (e.g., Dauphin and Williams 2004; Kohn_1999).

\footnotetext{
*Email: mathieu.duval@cenieh.es
} 


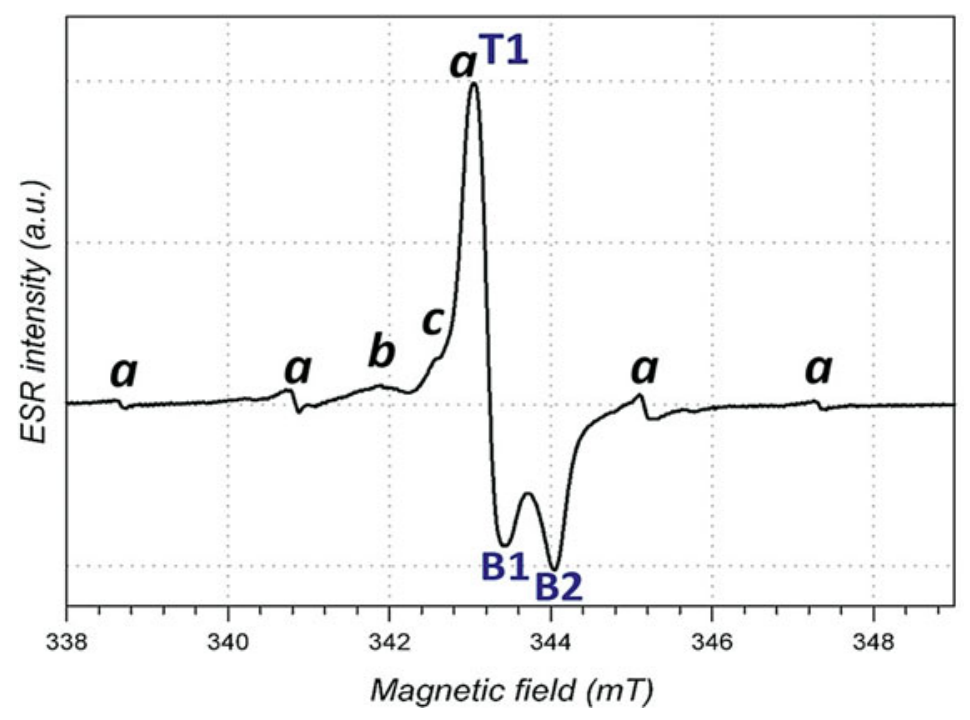

Fig. 1 ESR spectrum of fossil tooth enamel. In addition to the main radiation-induced ESR signal generated by $\mathrm{CO}_{2}{ }^{-}$ radicals, there are several minor contributions from other species (see Grün 2000a and references therein): (i) there is a septet centered on the main $\mathrm{CO}_{2}{ }^{-}$signal at $\mathrm{g}=2.0032$ (labeled "a"; only five lines are visible on that magnetic field range) formed by a free dimethyl radical; (ii) another isotropic line (marked " $b$ ") at $g=2.0115$ might be attributed to $\mathrm{CO}_{3}{ }^{-}$; and (i) the isotropic line at $\mathrm{g}=2.0056$ (marked "c") is usually attributed to a free radical, probably $\mathrm{SO}_{2}{ }^{-}$. In ESR dating, ESR intensities are usually extracted by peak-to-peak measurement between T1 and B2

The dosimetric properties of tooth enamel have been known for more than 40 years (e.g., Brady et al. 1968), and ESR is capable of measuring absorbed dose from only a few tens of mGy to several thousands of Gy (e.g., Fattibene and Callens 2010; Duval et al. 2009). Enamel is now internationally recognized as a valuable natural ESR biodosimeter, especially used in the field of retrospective dosimetry for persons accidentally exposed to ionizing radiations (e.g., IAEA 2002 and references therein).

\section{ESR Signal of Tooth Enamel}

The ESR signal of tooth enamel is an asymmetric composite signal defined by three peaks at $\mathrm{g} \sim 2.0032$ (T1), $\mathrm{g} \sim 2.0006$ (B1), and $\mathrm{g} \sim 1.9971$ (B2) (Fig. 1). Although many contributors to this signal have been identified (mainly carbonate-derived radicals and some oxygen radicals: Callens et al. 1998; Fattibene and Callens 2010), the major contribution is related to $\mathrm{CO}_{2}{ }^{-}$radicals.

Up to seven types of $\mathrm{CO}_{2}{ }^{-}$radicals have been identified as contributing to the main radiationinduced ESR signal (Brik et al. 2000), but the system is nevertheless usually simplified by considering three main types of $\mathrm{CO}_{2}{ }^{-}$(Fattibene and Callens 2010; Joannes-Boyau and Grün 2011): one isotropic at $\mathrm{g}=2.0006$ and two anisotropic $\mathrm{CO}_{2}{ }^{-}$radicals, an axial one $\left(\mathrm{g}_{\perp} \sim 2.003\right.$; $\left.\mathrm{g}_{\|} \sim 1.997\right)$ and an orthorhombic one $\left(\mathrm{g}_{\mathrm{x}} \sim 2.003 ; \mathrm{g}_{\mathrm{y}} \sim 1.997\right.$ and $\left.\mathrm{g}_{\mathrm{z}} \sim 2.001\right)$. These $\mathrm{CO}_{2}{ }^{-}$ radicals are usually divided in two categories: the non-oriented radicals, which exhibit a powder spectrum, and the oriented $\mathrm{CO}_{2}{ }^{-}$radicals, whose ESR signal may significantly change according to the angular position of the enamel fragment in the ESR cavity. Both groups have different characteristics in terms of thermal stability or microwave saturation. Furthermore, their relative proportions in the ESR signal may not be the same in the natural and irradiated spectrum. Irradiation or heating processes might induce some transformation from one category to another, 

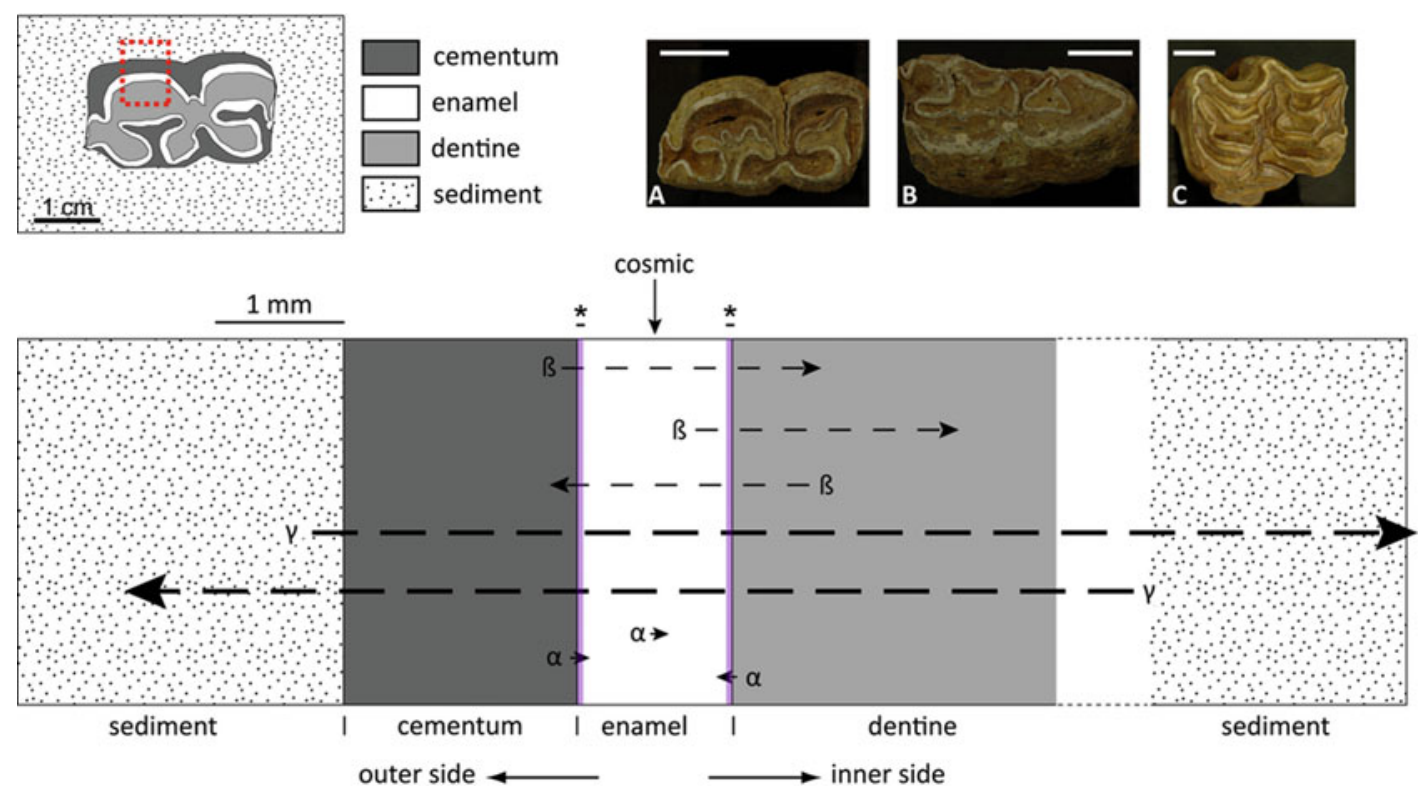

Fig. 2 Tooth geometry for dose rate calculations (Modified from Rink 1997). Shown here is the sediment-cementumenamel-dentine geometry. $\left(^{*}\right)$ is the removed enamel thicknesses (a few tens of $\mu \mathrm{m}$ ) from both sides of the enamel layer. Top right: examples of occlusal views of horse fossil teeth $(\mathbf{a}, \mathbf{b}$, and $\mathbf{c})$ from various Spanish archaeological sites $($ scale $=1 \mathrm{~cm})$

which would generate some uncertainties in the evaluation of $D_{E}$ (Joannes-Boyau and Grün 2011; Brik et al. 2000).

\section{Age and Dose Rate Equations}

The basic ESR age equation for tooth dating may be expressed as follows:

$$
D_{E}=\int_{0}^{T} D(t) d t
$$

where $D_{E}$ is the equivalent dose, i.e., the total dose (Gy) absorbed by the enamel during the time elapsed between the death of the animal $(\mathrm{t}=0)$ and the sampling $(\mathrm{t}=\mathrm{T})$, and $D(t)$ is the mean dose rate (in Gy/ka or $\mu \mathrm{Gy} / \mathrm{a}$ ).

Basically, the total dose accumulated in the enamel over time is the result of a combination of various contributions coming from radioactivity in the tooth itself and the surrounding environment. The specificity of tooth dating relies on the complex system that has to be considered. Indeed, a tooth is usually made by several tissues of varied thickness and composition. Therefore, accurate age calculation must rely on careful consideration of the geometry of the enamel layer and its surrounding environment.

Except for the cosmic dose, each component of the dose rate is directly derived from the contributions of the $\alpha$-particles, $\beta$-particles, and $\gamma$-rays emitted by the radioactive elements located within the sample and its surrounding environment (mainly $U$ and Th decay products as well as $\left.{ }^{40} \mathrm{~K}\right)$. Because each kind of ionizing radiation has a specific penetration range in matter $(\sim 20-40 \mu \mathrm{m}$ 
for $\alpha$-particles, $\sim 2 \mathrm{~mm}$ for $\beta$-particles, and $\sim 30 \mathrm{~cm}$ for $\gamma$-rays), some of their respective contribution has to be attenuated or even removed depending on the size of the sample dated.

For dental tissues, only the $U$ decay products contribute significantly to the enamel dose, because tissues are usually assumed to be free of Th decay products as well as ${ }^{40} \mathrm{~K}$ (e.g., Grün and McDermott 1994). Given the typical thickness of the enamel (a few mm), it is usually assumed that self-absorption of internal $\gamma$-rays is negligible. Thus, the internal dose rate from the enamel is only made by $\alpha$ - and $\beta$-components, which are corrected by an alpha efficiency factor and a selfabsorption factor, respectively. For the other tissues, we need to consider only an attenuated beta component, since the external $\alpha$-particle contribution is removed by abrading both sides of the enamel layer over a few tens of $\mu \mathrm{m}$. The magnitude of the beta component depends on the initial and removed thicknesses of the enamel layer as well as water content in the tissues. Finally, the sediment typically provides only a $\gamma$-ray contribution to dose rate (unless the enamel is in direct contact with sediment), corrected by water attenuation, and derived from the measured elemental concentrations of $\mathrm{U}$, Th, and $\mathrm{K}$. Consequently, in case of a geometry sediment-cementum-enameldentine (Fig. 2), the dose rate equation may be expressed as follows:

$$
\begin{aligned}
& D(t)= \\
& {\left[D_{\alpha}(t)+D_{\beta}(t)\right]_{\text {enamel }}+\left[D_{\beta}(t)\right]_{\text {dentine }}+\left[D_{\beta}(t)\right]_{\text {cementum }}+\left[D_{\gamma}(t)\right]_{\text {sediment }}+} \\
& D_{\text {cosmic }}(t)= \\
& {\left[C_{U}(t)\left(F_{U \alpha} k+F_{U \beta} S_{U \beta}\right)\right]_{\text {ena. }}+\left[C_{U}(t) F_{U \beta} A_{\beta 1} W_{\beta}\right]_{\text {dent. }}+\left[C_{U}(t) F_{U \beta} A_{\beta 2} W_{\beta}\right]_{\text {cem. }}+} \\
& {\left[C_{U}(t) F_{U \gamma} W_{\gamma}+C_{T h}(t) F_{T h \gamma} W_{\gamma}+C_{K}(t) F_{K \gamma} W_{\gamma}\right]_{\text {sed. }}+D_{\text {cos. }}(t)}
\end{aligned}
$$

where $\mathrm{C}_{\mathrm{U}}, \mathrm{Th}, \mathrm{K}$ is the concentration in $\mathrm{U}$, Th, and $\mathrm{K}$ measured in each dental tissue and sediment; $\mathrm{W}_{\alpha, \beta, \gamma}$ is the water attenuation for $\alpha$-particles, $\beta$-particles, and $\gamma$-rays; $\mathrm{F}_{\mathrm{U}, \mathrm{Th}, \mathrm{K} ; \alpha, \beta, \gamma}$ is the dose rate conversion factor depending on the kind of ionizing radiation and the emitter; $\mathrm{k}$ is the alpha efficiency; $S_{U \beta}$ is the internal beta self-absorption; and $A_{\beta 1,2}$ is the external beta attenuation for $U$ series elements. Equation (2) is valid when equilibrium is assumed within the U-series or Th-series decay products in the dental tissues and sediment. However, if disequilibrium is observed, more elements in each decay series have to be considered in the equation. Specific issues with disequilibrium in dental tissues and sediment may be found in Grün (1989) and Olley et al. (1996), respectively.

In case of enamel in direct contact with the sediment, Eq. (2) has to be modified by considering an external beta contribution from the sediment, instead of a tissue.

\section{U-Uptake Modeling}

Dental tissues behave as open systems for U-series elements. It is therefore crucial not only to measure the U-content but also to know its past evolution. To address this point, several parametric U-uptake models were proposed. The early uptake (EU) model assumes that $U$ is incorporated shortly after burial (Bischoff and Rosenbauer 1981), i.e., an approximation of a closed system. The linear U-uptake (LU) model describes uptake with a constant rate since the time of burial (Ikeya 1982). The recent uptake (RU) model considers that all measured U-concentration in the sample was taken up in very recent times (Blackwell et al. 1992). These parametric models allow some easy age calculations, but are based on unrealistic assumptions (i.e., the closed system assumption for the EU uptake). Additionally, the models oversimplify the complexity of U-uptake into the different tissues in some teeth (e.g., Grün 2009a). These models cause large uncertainties when 
uranium concentrations in the dental tissues are high, and the calculated age value may be very sensitive to the U-uptake assumption (e.g., Grün and McDermott 1994; Duval et al. 2012).

To address the problem of the unknown U-uptake, Grün et al. (1988) suggested to combine ESR and U-series analyses and introduced a parameter $p$ to describe the kinetics of the U-uptake in the dental tissue (US model). In comparison with the conventional models, the combined US-ESR method has the advantage that U-uptake history is not a priori assumed, but mathematically assessed according to the ESR and present-day U-series (U-concentration, ${ }^{230} \mathrm{Th} /{ }^{234} \mathrm{U}$ and ${ }^{234} \mathrm{U} /{ }^{238} \mathrm{U}$ ) data measured in each tissue. As a consequence, only one combined US-ESR age fits the available dataset (Grün et al. 1988). Moreover, the US-ESR approach considers the possibility of different uptake histories among the various dental tissues of a unique tooth, by calculating a specific $p$-parameter for each tissue. This approach also helps to overcome some limitations of the U-series dating method in some specific situations, beyond the time range of the U-series dating method (Grün et al. 2010) or in case of very recent U-uptake (e.g., Falguères et al. 2006).

However, the combined US-ESR approach has also several limitations. First, U-leaching from dental tissue cannot be modeled (Grün et al. 1988). By definition, the U-uptake history is mainly modeled from the U-series data measured in dental tissues. Consequently, the reliability of the calculated age is highly dependent on the accuracy of these U-series data. However, the latter may be influenced by many factors, such as the spatial homogeneity and preservation of the sample, or recent U-mobilization that may overprint past U-uptake history (Duval et al. 2011). Other models based on the combination of U-series and ESR data have been also developed, in particular to specifically address the issue raised by the occurrence of U-leaching in dental tissue (e.g., Shao et al. 2012) or the spatial variation of the U-series data (Pike et al. 2001), but their potential and limitations are not clearly defined yet. Finally, another variation of the US model was also proposed by Grün (2000), the closed system (CS)-US model. This is based on a very specific assumption, i.e., the measured uranium content was incorporated into the tissues at the time corresponding to the apparent $\mathrm{U}$-series age, providing thus a maximum possible age for the sample.

\section{Standard Analytical Procedure: A Brief Overview}

An ESR age estimate is the result of a long and complex analytical process, made by several steps associating fieldwork and laboratory procedures, which may be resumed as follows:

Sampling. Fossil teeth are collected directly from the site or chosen from collections. In situ measurements of the natural radioactivity should be performed at the exact place, or at least the closest possible, where the sample was collected.

Sample preparation. In the laboratory, the tooth is prepared by separating mechanically each dental tissue. The enamel is then cleaned on both sides to remove external $\alpha$-particles contribution and powdered, in order to avoid angular dependence of the ESR signal within the ESR resonator and to improve sample homogeneity.

D $_{\mathbf{E}}$ reconstruction by ESR spectrometry. The enamel powder is usually divided in one or several subsample aliquots that are irradiated at various increasing dose steps (additive dose method). Each aliquot is then measured at room temperature by X-band ESR spectrometry in order to study the behavior of the ESR signal with the increasing dose values. The ESR intensity is extracted from each spectrum, usually by peak-to-peak measurements between T1 and B2 (Fig. 1). A mathematical function, usually a single saturating exponential or a double-saturating exponential function (Duval et al. 2009), is fitted through the experimental data points and its extrapolation to 


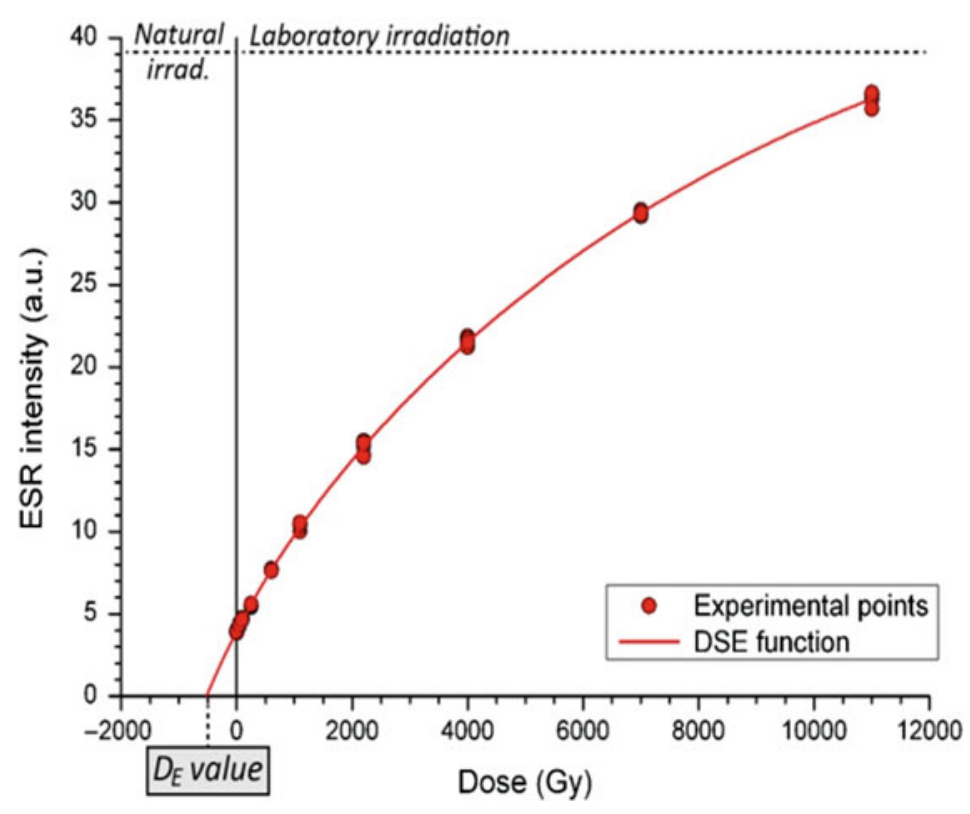

Fig. 3 Example of ESR dose-response curve. A double-saturating exponential (DSE) function is fitted through the experimental points, and $\mathrm{D}_{\mathrm{E}}$ is obtained by extrapolation of the function to $\mathrm{Y}=0$

the abscissa axis $(\mathrm{Y}=0)$ provides the $\mathrm{D}_{\mathrm{E}}$ value, corresponding the total dose absorbed by the tooth enamel since the death of the animal (Fig. 3).

Evaluation of dose rate. If the gamma dose rate has to be assessed in situ, the external beta dose rate contribution coming from the sediment should be assessed in the laboratory, from the sediment sample that was collected around the tooth. Usually, the dose rate is derived from the activities or concentrations of the radioactive elements present in the sample and its surroundings. These concentration data are converted into dose values using known factors (Adamiec and Aitken 1998) and corrected according to several parameters, such as the water content (e.g., Grün 1994), the geometry of the sample, its thickness and density for $\beta$-attenuations (Brennan et al. 2000), and the alpha efficiency (Grün and Katzenberger-Apel 1994). In case of the combined USESR approach, U-series data from each dental tissue (U-content ${ }^{234} \mathrm{U} /{ }^{238} \mathrm{U}$ er ${ }^{230} \mathrm{Th} /{ }^{234} \mathrm{U}$ ) is required in order to model the uranium uptake. Finally, the cosmic dose rate contribution is usually assessed via tables and is corrected according to various factors like the ground density, depth of the sample, altitude, and latitude (Prescott and Hutton 1994).

ESR age estimate. Basically, two main noncommercial programs are most widely used for age calculation on teeth: these are the ROSY software which enables age calculation based on the parametric U-uptake models (Brennan et al. 1999) and the DATA program, providing combined US-ESR age estimates (Grün 2009b). ESR ages are usually quoted \pm one standard deviation. Relative age uncertainties are rarely $<10 \%$ (Rink 1997) and are more likely between $10 \%$ and $20 \%$.

\section{Time Range Applicability}

It is usually considered that the optimum time range application for ESR dating of tooth enamel lies between $\sim 50$ and $\sim 600 \mathrm{ka}$. Nevertheless, under some specific conditions, the time range limits may be potentially pushed from $<1$ ka to $\sim 2-3$ Ma. 
For modern ESR samples, the lower dating range is in general mainly driven by (i) the radiation sensitivity of the material and (ii) the sensitivity of the tools employed for dose reconstruction, including the ESR spectrometer. Recent developments in ESR dosimetry of enamel lead to define a detection limit of several tens of mGy (Fattibene and Callens 2010). The detection of background dose values with ESR spectrometry (e.g., Toyoda et al. 2011) suggests the possibility of dating almost present-day (i.e., last millennium) materials, as soon as radionuclide concentrations in the sample and its surrounding environment can be accurately assessed. However, a rapid overview of the published works indicates that ESR dating is rarely applied to fossil teeth younger than $\sim 20 \mathrm{ka}$.

The upper limit of the datable age range is mainly constrained by two parameters: (i) the saturation of the ESR signal with the absorbed dose and (ii) the thermal stability of the paramagnetic centers. Depending on the number of traps available in the crystal lattice, the nature of the analyzed paramagnetic center; and the intensity of the dose rate, the intensity of the ESR signal may saturate rapidly or more slowly when the material is absorbing ionizing radiations. In the case of teeth, the saturation level in enamel is very high and absorbed dose values up to several thousands of Gy have been detected (e.g., Duval et al. 2009). The second parameter is the thermal stability of the paramagnetic centers, which describes the mean life of a trapped electron at the defect site. Schwarcz (1987) assessed the lifetime of the ESR signal of tooth enamel to $\sim 1 \mathrm{Ga}$ at $25^{\circ} \mathrm{C}$, suggesting then a possible application over a few Ma. As a rule of thumb, the ESR signal must have a mean life of at least one order of magnitude higher than the age of the sample dated (Grün 2007) in order to avoid systematic uncertainties due to decay of the signal during burial. However, when dealing with old samples ( $>800 \mathrm{ka}$ ), the main complication lies in the U-uptake modeling for the dose rate reconstruction. Indeed, U-leaching may be frequently observed for such time range, making the application of the combined US-ESR approach extremely difficult (e.g., Duval et al. 2012). Only two situations are possible in which ESR dating could potentially be accurate to ages up to 2-3 Ma: (i) no apparent U-leaching is detected in dental tissues, which may sometimes occur for Early Pleistocene sites (e.g., Duval et al. 2012), or (ii) the tooth samples show very low Uconcentration in dental tissues (e.g., Schwarcz et al. 1994), decreasing the relative contribution of dental tissues in the total dose rate calculation in comparison with sediment.

\section{Main Strengths and Weaknesses of the ESR Dating Method Applied to Fossil Teeth}

ESR dosimetry of tooth enamel is now an international reference method (Fattibene and Callens 2010), demonstrating the great potential of this material for dose reconstruction. In addition, ESR is one of the very few dating methods that may be applied to fossil remains and can provide a direct measurement of age of hominid or animal occupation in any sedimentary context. ESR dating is also one of the very few alternatives for dating fossils, including hominid remains, beyond the ${ }^{14} \mathrm{C}$ and U-series dating time range (Grün et al. 2010).

In contrast, the complexity and the length of the analytical process are likely the main limitations of this dating method. Many parameters $(>15)$ have to be considered and assessed for the age calculation, with a direct consequence on the age precision (final age errors are usually $>10 \%$ ). In addition, at least several months are usually required to fully process a sample, and the analytical procedure involves an array of equipment that must be carefully and accurately calibrated (e.g., Useries analyses facilities, ESR spectrometer, gamma irradiation source, high-resolution gamma spectrometer, portable gamma spectrometer). Finally, another limitation lies in the sampling itself. In the case of historic excavations, it may be difficult to precisely locate (geographically and 
stratigraphically) the sample's provenance, which induce many uncertainties on the external dose rate associated to sediment and thus on the final age estimate.

\section{Some Examples of Recent Developments in the Field}

\section{ESR Measurement of Enamel Fragments}

Working with enamel fragments significantly reduces the destructive aspect of the method. However, this technique implies a complex analytical procedure (e.g., Joannes-Boyau and Grün 2011). Nevertheless, ESR analyses of enamel fragments, unlike powder, may provide useful information about the composition of the ESR signal: each component contributing to the radiation-induced ESR signal may be potentially isolated and studied separately, which may be of special interest for reducing potential source of error in the $D_{E}$ assessment (Joannes-Boyau and Grün 2011).

\section{High-Resolution Mapping of Radioelement Distribution in Dental Tissues}

The combination of a laser ablation system with an ICP-MS (LA-ICP-MS) recently opened huge perspectives for the U-series analyses of dental tissues (e.g., Eggins et al. 2003), yielding highresolution U-series data in a short acquisition time and with minor sample preparation. For example, maps of spatial distribution of U-series elements in dental tissues may be obtained (e.g., Duval et al. 2011). This is of special interest for studying U-mobility into dental tissues and may be particularly useful to identify domains in the teeth that are suitable for ESR dating.

\section{Direct Dating of Hominid Remains}

The recent development of ESR measurements on enamel fragments combined with LA-ICP-MS U-series analysis now permits analysis of human teeth without causing any visible damage (e.g., Grün et al 2006). Such an approach offers new perspectives for the ESR method, by giving access to direct dating of inestimable hominid remains that are beyond the ${ }^{14} \mathrm{C}$ time range.

\section{ESR Dating of Early Pleistocene Fossil Teeth}

"Old" samples result in many challenges that are not encountered in younger samples and which make the application of the combined US-ESR approach especially complex (see Duval et al. 2012 for further details). Nevertheless, recent methodological developments showed that ESR may, a useful tool to constrain the chronology of the earliest hominid occupations in Eurasia and Africa during Early Pleistocene times (e.g., Duval et al. 2012).

\section{Summary}

ESR dating is one of the very few dating methods that may be applied to fossil remains, resulting in a direct measurement of the age of hominid or animal occupations in any sedimentary context. The challenge in applying ESR dating to fossil teeth lies in the requirement to model U-uptake kinetics into each dental tissue, which is known to behave as open systems for U-series elements. So far, the combined (or coupled) U-series/ESR dating approach provides the most reliable results through a combination of U-series and ESR data to obtain an ESR age estimate. Under some specific conditions, this application may potentially cover the whole Quaternary time range. 


\section{Cross-References}

Q4 Electron Spin Resonance Dating

- Electron Spin Resonance Spectrometer

$\checkmark$ Electron Spin Resonance, Coral

- Electron Spin Resonance, Mollusc

$\checkmark$ Electron Spin Resonance, Sediment

- Electron Spin Resonance-Uranium Series, Teeth

$\checkmark$ Geochronology

- Hominid Evolution Timescale

- Quartz Defects, Optically Stimulated Luminescence and Thermoluminescence

- Radiation and Radioactivity

$>$ Radiation Defect

- Radiation Dose Rate

$\checkmark$ Uranium Series Dating

- Uranium Series Gamma Spectrometric, Bones

- Uranium Series, Bones

\section{Bibliography}

Brennan, B. J., Rink, W. J., Rule, E. M., Schwarcz, H. P., and Prestwich, W. V., 1999. The ROSY ESR dating program. Ancient TL, 17(2), 45-53.

Brennan, B. J., Prestwich, W. V., Rink, W. J., Marsh, R. E., and Schwarcz, H. P., 2000. Alpha and beta dose gradients in tooth enamel. Radiation Measurements, 32(5-6), 759-765.

Brik, A. B., Rosenfeld, L. G., Haskell, E. H., Kenner, G. H., and Brik, V. B., 2000. Formation mechanism and localization places of $\mathrm{CO}_{2}{ }^{-}$radicals in tooth enamel. Mineral Journal (Ukraine), 22(5/6).

Callens, F., Vanhaelewyn, G., Matthys, P., and Boesman, E., 1998. EPR of carbonate derived radicals: applications in dosimetry, dating and detection of irradiated food. Applied Magnetic Resonance, 14(2-3), 235-254.

Duval, M., Grün, R., Falguères, C., Bahain, J. J., and Dolo, J. M., 2009. ESR dating of Lower Pleistocene fossil teeth: limits of the single saturating exponential (SSE) function for the equivalent dose determination. Radiation Measurements, 44(5-6), 477-482.

Duval, M., Aubert, M., Hellstrom, J., and Grün, R., 2011. High resolution LA-ICP-MS mapping of $\mathrm{U}$ and Th isotopes in an early Pleistocene equid tooth from Fuente Nueva-3 (Orce, Andalusia, Spain). Quaternary Geochronology, 6(5), 458-467.

Duval, M., Falguères, C., and Bahain, J.-J., 2012. Age of the oldest hominin settlements in Spain: contribution of the combined U-series/ESR dating method applied to fossil teeth. Quaternary Geochronology, 10, 412-417.

Eggins, S., Grün, R., Pike, A. W. G., Shelley, M., and Taylor, L., 2003. 238U, 232Th profiling and U-series isotope analysis of fossil teeth by laser ablation-ICPMS. Quaternary Science Reviews, 22(10-13), 1373-1382.

Elliott, J., 2002. Calcium phospahte biominerals. In Kohn, M. J., Rakovan, J., and Hughes, J. M. (eds.), Phosphates - Geochemical, Geobiological and Material Importance. Washington, DC: Mineralogical Society of America, p. 427e454. 
Falguères, C., Bahain, J.-J., Pérez-González, A., Mercier, N., Santonja, M., and Dolo, J.-M., 2006. The Lower Acheulian site of Ambrona, Soria (Spain): ages derived from a combined ESR/Useries model. Journal of Archaeological Science, 33(2), 149-157.

Fattibene, P., and Callens, F., 2010. EPR dosimetry with tooth enamel: a review. Applied Radiation and Isotopes, 68(11), 2033-2116.

Grün, R., 1994. A cautionary note: use of 'water content' and 'depth for cosmic ray dose rate' in AGE and DATA programs. Ancient $T L, \mathbf{1 2}(2), 50-51$.

Grün, R., 2000a. An alternative model for open system U-series/ESR age calculations: (closed system U-series)-ESR, CSUS-ESR. Ancient TL, 18(1), 1-4.

Grün, R., 2000b. Methods of dose determination using ESR spectra of tooth enamel. Radiation Measurements, 32(5-6), 767-772.

Grün, R., 2007. LUMINESCENCE DATING I Electron Spin Resonance Dating. In Scott, A. E. Editor-in-Chief, Encyclopedia of Quaternary Science. Oxford: Elsevier, pp. 1505-1516.

Grün, R., 2009a. The relevance of parametric U-uptake models in ESR age calculations. Radiation Measurements, 44(5-6), 472-476.

Grün, R., 2009b. The DATA program for the calculation of ESR age estimates on tooth enamel. Quaternary Geochronology, 4(3), 231-232.

Grün, R., and Katzenberger-Apel, O., 1994. An alpha irradiator for ESR dating. Ancient TL, 12(2), 35-38.

Grün, R., and McDermott, F., 1994. Open system modelling for U-series and ESR dating of teeth. Quaternary Science Reviews, 13(2), 121-125.

Grün, R., and Schwarcz, H. P., 1987. Some remarks on ESR dating of bones. Ancient TL, 5(2), 1-9.

Grün, R., Maroto, J., Eggins, S., Stringer, C., Robertson, S., Taylor, L., Mortimer, G., and McCulloch, M., 2006. ESR and U-series analyses of enamel and dentine fragments of the Banyoles mandible. Journal of Human Evolution, 50(3), 347-358.

Grün, R., Aubert, M., Hellstrom, J., and Duval, M., 2010. The challenge of direct dating old human fossils. Quaternary International, 223-224, 87-93.

IAEA, 2002. Use of the electron paramagnetic resonance dosimetry with tooth enamel for retrospective dose assessment. In IAEA-TECDOC-1331, International Atomic Energy Agency, Vienna, p. 57.

Ikeya, M., 1982. A model of linear uranium accumulation for ESR age of Heidelberg (Mauer) and Tautavel bones. Japanese Journal of Applied Physics, 21, 690-692.

Ikeya, M., and Miki, T., 1980. Electron spin resonance dating of animal and human bones. Science, 207(4434), 977-979.

Joannes-Boyau, R., and Grün, R., 2011. A comprehensive model for $\mathrm{CO}_{2}{ }^{-}$radicals in fossil tooth enamel: implications for ESR dating. Quaternary Geochronology, 6(1), 82-97.

Olley, J. M., Murray, A., and Roberts, R. G., 1996. The effects of disequilibria in the uranium and thorium decay chains on burial dose rates in fluvial sediments. Quaternary Science Reviews, 15(7), 751-760.

Pike, A. W. G., and Hedges, R. E. M., 2001. Sample geometry and U uptake in archaeological teeth: implications for U-series and ESR dating. Quaternary Science Reviews, 20(5-9), 1021-1025.

Prescott, J. R., and Hutton, J. T., 1994. Cosmic ray contributions to dose rates for luminescence and ESR dating: large depths and long-term time variations. Radiation Measurements, 23(2-3), 497-500.

Rink, W. J., 1997. Electron spin resonance (ESR) dating and ESR applications in quaternary science and archaeometry. Radiation Measurements, 27(5-6), 975-1025. 
Schwarcz, H. P., 1985. ESR studies of tooth enamel. Nuclear Tracks and Radiation Measurements (1982), 10(4-6), 865-867.

Schwarcz, H. P., Grün, R., and Tobias, P. V., 1994. ESR dating studies of the australopithecine site of Sterkfontein, South Africa. Journal of Human Evolution, 26(3), 175-181.

Shao, Q., Bahain, J.-J., Falguères, C., Dolo, J.-M., and Garcia, T., 2012. A new U-uptake model for combined ESR/U-series dating of tooth enamel. Quaternary Geochronology, 10, 406-411.

Toyoda, S., Kondo, A., Zumadilov, K., Hoshi, M., Miyazawa, C., and Ivannikov, A., 2011. ESR measurements of background doses in teeth of Japanese residents. Radiation Measurements, 46(9), 797-800. 


\section{Author Queries}

\begin{tabular}{|c|c|}
\hline Query Refs. & Details Required \\
\hline Q1 & $\begin{array}{l}\text { Please provide details of Grün et al. (1988), Dauphin and Williams (2004), Kohn (1999), Brady } \\
\text { et al. (1968) Grün (1989), Bischoff and Rosenbauer (1981), Blackwell et al. (1992), Pike et al. } \\
\text { (2001), Adamiec and Aitken (1998), Schwarcz (1987) in the reference list. }\end{array}$ \\
\hline Q2 & $\begin{array}{l}\mathrm{C}_{\mathrm{U}}, \mathrm{Th}, \mathrm{K}, \mathrm{U}, \mathrm{W}_{\alpha, \beta}, \gamma, \mathrm{F}_{\mathrm{U}}, \mathrm{k}, \mathrm{S}_{\mathrm{U} \beta}, \mathrm{A}_{\beta} \text { in equation and text are given in both roman and } \\
\text { italic. Please confirm which form has to be made consistant. }\end{array}$ \\
\hline Q3 & Please specify whether "a” or "b" for Grün (2000). \\
\hline Q4 & $\begin{array}{l}\text { Cross-References "Electron Spin Resonance Dating", "Electron Spin Resonance, Coral", } \\
\text { "Electron Spin Resonance, Mollusc", "Electron Spin Resonance, Sediment", "Electron Spin } \\
\text { Resonance-Uranium Series, Teeth", "Uranium Series Dating", "Uranium Series Gamma } \\
\text { Spectrometric, Bones" "Uranium Series, Bones" does not match with TOC. Please check. }\end{array}$ \\
\hline Q5 & Please provide page range for Brik et al. (2000). \\
\hline
\end{tabular}

